\title{
TLR4 single nucleotide polymorphisms (SNPs) associated with Salmonella shedding in pigs
}

\author{
Jalusa Deon Kich • Jolita Janutenaite Uthe • Magda Vieira Benavides • \\ Maurício Egídio Cantão • Ricardo Zanella • Christopher Keith Tuggle • \\ Shawn Michelle Dunkin Bearson
}

Received: 8 July 2013 / Revised: 29 January 2014 / Accepted: 4 February 2014 /Published online: 25 February 2014

(C) The Author(s) 2014. This article is published with open access at Springerlink.com

\begin{abstract}
Toll-like receptor 4 (TLR4) is a key factor in the innate immune recognition of lipopolysaccharide (LPS) from Gram-negative bacteria. Previous studies from our group identified differences in the expression profile of TLR4 and genes affected by the TLR4 signaling pathway among pigs that shed varying levels of Salmonella, a Gram-negative bacterium. Therefore, genetic variation in this gene may be involved with the host's immune response to bacterial infections. The current study screened for single nucleotide polymorphisms (SNPs) in the TLR4 gene and tested their association with Salmonella fecal shedding. Pigs $(n=117)$ were intranasally challenged at 7 weeks of age with $1 \times 10^{9} \mathrm{CFU}$ of $S$. Typhimurium $\chi 4232$ and were classified as low or persistent Salmonella shedders based on the levels of Salmonella being excreted in fecal material. Salmonella fecal shedding was determined by quantitative bacteriology on days
\end{abstract}

Electronic supplementary material The online version of this article (doi:10.1007/s13353-014-0199-8) contains supplementary material, which is available to authorized users.

J. D. Kich $(\bowtie) \cdot$ J. J. Uthe $\cdot$ S. M. D. Bearson

USDA/ARS/National Animal Disease Center, 1920 Dayton Ave,

Ames, IA, USA

e-mail: jalusa.kich@embrapa.br

J. D. Kich • M. E. Cantão

Embrapa Swine and Poultry, Br 153, Km 110, Concórdia, SC, Brazil

J. J. Uthe $\cdot$ C. K. Tuggle

Department of Animal Science, Iowa State University, 2255 Kildee

Hall, Ames, IA, USA

M. V. Benavides

Embrapa LabEx USA/USDA, Beltsville Agriculture Research

Center, Beltsville, MD, USA

R. Zanella

Embrapa Swine and Poultry BJT/CNPq, Br 153, Km110, Concórdia, SC, Brazil
$2,7,14$, and 20/21 post exposure, and the cumulative levels of Salmonella were calculated to identify the low $(n=20)$ and persistent $(n=20)$ Salmonella shedder pigs. From those 40 animals, the TLR4 region was sequenced, and 18 single nucleotide polymorphisms (SNPs) in TLR4 were identified. Twelve SNPs have been previously described and six are novel SNPs of which five are in the $5^{\prime}$ untranslated region and one is in intron 2. Single marker association test identified 13 SNPs associated with the qualitative trait of Salmonella fecal shedding, and seven of those SNPs were also associated with a quantitative measurement of fecal shedding $(P<0.05)$. Using a stepwise regression process, a haplotype composed of SNPs $r s 80787918$ and $r s 80907449\left(P \leq 4.0 \times 10^{-3}\right)$ spanning a region of $4.9 \mathrm{~Kb}$ was identified, thereby providing additional information of the influence of those SNPs on Salmonella fecal shedding in pigs.

Keywords Salmonella $\cdot$ Single nucleotide polymorphisms (SNPs) · Swine $\cdot$ TLR4

\section{Introduction}

Salmonella is a widespread foodborne pathogen with the ability to adapt to different environments, consequently creating significant challenges to food-producing industries in controlling this pathogen in food chain products. Swine (Sus scrofa) are an important reservoir of Salmonella because colonization and shedding of this bacterium occurs within asymptomatic pigs, imposing elevated risks to public and animal health. Thus, diverse intervention strategies are needed to control the transmission of Salmonella from pig products to humans and to the environment.

In bacterial infections, the severity of infection is impacted by the pathogenicity of the microorganism and its interaction with the host immune defense system (Zanella et al. 2011). 
Toll-like receptor 4 (TLR4) is a well-characterized gramnegative bacterial lipopolysaccharide (LPS) recognition receptor and a host inflammatory response activator well conserved among animal species (Noreen et al. 2012; Yang et al. 2012). Schröder and Schumann (Schröder and Schumann 2005) suggested that mutations in the TLR4 regions involved with pathogen recognition and transduction signaling may affect host susceptibility to infection. Polymorphisms in the TLR4 gene have been associated with different infectious diseases in humans, such as meningitis and tuberculosis, as well as some types of cancers (Noreen et al. 2012) and with infection and disease in cattle, chicken and pigs (Yang et al. 2012; Kataria et al. 2011; Leveque et al. 2003).

In swine, TLR4 is located on Sus scrofa 1 (SSC1) V10.2 (289,776,058 bp to $289,785,087 \mathrm{bp})$. Thomas et al. (2006) identified the genomic structure of porcine TLR4, and Shinkai et al. (2006) described the distribution of SNPs for five TLRs in pigs. Specifically for TLR4, 13 SNPs were widely distributed in 11 pig breeds, and of those, seven were nonsynonymous. Thirty four SNPs were identified in TLR4 using pigs representing European commercial breeds and some traditional breeds $(n=259)$, and of these, 17 SNPs were located in the non-coding region and 17 SNPS were found in the coding region (Palermo et al. 2000). Furthermore, polymorphisms in the TLR4 gene have been identified as potential genetic markers for disease susceptibility in pigs (Uenishi and Shinkay 2009). Our collaborative group has reported upregulation of TLR 4 and its target genes in pigs challenged with Salmonella enterica serovar Typhimurium (Huang et al. 2011). Therefore, to determine if TLR 4 is a possible candidate gene associated with Salmonella shedding, we first, identified SNPs in the TLR4 gene of our previously described low and persistent shedder pig populations (Huang et al. 2011; Uthe et al. 2009, 2011). Second, we investigated associations of the TLR4 SNPs with Salmonella shedding status. Selecting for pigs with reduced Salmonella fecal shedding would decrease environmental contamination and lower pathogen transmission to other animals and humans; thus, identification of loci in TLR4 associated with Salmonella fecal shedding is the focus of this study.

\section{Material and methods}

All procedures involving animals in the NADC-40 and NADC-77 populations were approved by the USDA, ARS, NADC Animal Care and Use Committee. Briefly, all the pigs used in this study were intranasally challenged at 7 weeks of age with $1 \times 10^{9} \mathrm{CFU}$ of $S$. Typhimurium $\chi 4232$ as previously described (Huang et al. 2011; Uthe et al. 2009). At days 2, 7 , 14 , and 20/21 post-inoculation (pi), Salmonella fecal shedding was quantified using a standard bacteriological test previously described (Uthe et al. 2009).
Of the initial 117 animals, $40(n=40)$ pigs were chosen based on their extreme fecal culture status; quantitative classification of the phenotype was scored based on cumulative Salmonella fecal shedding on days 2, 7, 14, and 20/21 pi (Huang et al. 2011). Genomic DNA was extracted from blood samples and purified as previously described (Uthe et al. 2011). Nine sets of primers were designed based on the Ensembl gene sequence for ENSSSCG00000005503 using Beacon Designer (Table 1). Primers were selected to cover all exons $(n=3)$ of TLR 4 including a 713 bp upstream region and a 1225 bp downstream region (SSC1: 289,775,345 bp$289,786,312$ bp Ensembl genome build 10.2). The PCR mix

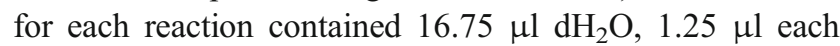
primer $(10 \mu \mathrm{M}), 2 \mu \mathrm{l}$ of dNTPs, $2.5 \mu \mathrm{l}$ 10X Buffer with $\mathrm{MgCl}_{2}, 0.25 \mu \mathrm{l}$ Platinum Taq DNA Polymerase High Fidelity (Invitrogen Grand Island, NY, USA) and $1 \mu 1$ of $10 \mathrm{ng} / \mu \mathrm{l} \mathrm{pig}$ DNA. DNA samples were amplified using the MJ Research PTC-200 PCR thermal cycler (BioRad Laboratories, Hercules, CA). The PCR reaction was performed as follows: $94{ }^{\circ} \mathrm{C}$ for $2 \mathrm{~min}, 30$ cycles of $94^{\circ} \mathrm{C}$ for $30 \mathrm{~s}, 58^{\circ} \mathrm{C}$ for $30 \mathrm{~s}, 72^{\circ} \mathrm{C}$ for $1 \mathrm{~min}$ and a final step of $72{ }^{\circ} \mathrm{C}$ for $7 \mathrm{~min}$. PCR products were visualized by agarose gel electrophoresis to confirm a single correct size product and purified using MinElute 96 UF PCR purification kit (Qiagen) prior to DNA sequencing using an AB 3730xl DNA Analyzer (Applied Biosystems) at Iowa State University, Ames, IA.

Sequences were analyzed and polymorphisms were identified using Phred/Phrap/Consed/PolyPhred software (Nickerson et al. 1997; Ewing et al. 1998; Gordon et al. 1998; [internet] http://www phrap org). Genotypic data were assessed for quality before the association analysis. SNPs were also assessed for quality prior to the association analysis. SNPs were removed if the minor allele frequency (MAF) was less than $10 \%$, if the SNPs failed to genotype in more than $10 \%$ of the samples, or if the SNPs failed the Hardy-Weinberg equilibrium $(P<0.001)$. No animals or SNPs were removed from the analysis due to genotypic quality. Statistical analyses were conducted within PLINK and R statistical environment (version 1.07, (Purcell et al. 2007)).

A chi-squared test $\left(\chi^{2}\right)$ was used to test associations of SNPs located in TLR4 and the qualitative measurement of Salmonella shedding (persistent versus low). The Wald test was used to verify associations with Salmonella shedding as a quantitative trait. A significance threshold for the association analysis was set to $P \leq 0.05$. Following the single marker association test, a haplotype test was conducted within PLINK to identify if a haplotype was more informative than a single SNP. First, an omnibus association test was performed to identify the overall association of the haplotype with the qualitative measurement of Salmonella shedding. If an association was identified, a haplotype-specific test was performed to identify which combination of the alleles provided the strongest evidence for an association with Salmonella 
Table 1 Identified SNPs and position in the TLR4 gene of Salmonella low and persistent shedder pigs

\begin{tabular}{|c|c|c|c|c|c|c|c|c|c|}
\hline \multirow[b]{2}{*}{$\mathrm{N}$} & \multirow[b]{2}{*}{ Location } & \multirow[b]{2}{*}{ Primers } & \multirow[b]{2}{*}{$\begin{array}{l}\text { SNP } \\
\text { designation }\end{array}$} & \multicolumn{2}{|c|}{$\begin{array}{l}\text { Single marker } \\
\text { association ( } P \text {-value })\end{array}$} & \multirow[t]{2}{*}{$\begin{array}{l}\text { GenBank accession } \\
\text { number for the SNP }\end{array}$} & \multirow[t]{2}{*}{$\begin{array}{l}\text { Location in Sus } \\
\text { Scrofa genome (bp) }\end{array}$} & \multicolumn{2}{|c|}{ Amino acid } \\
\hline & & & & Qualitative & Quantitative & & & Site & $\begin{array}{l}\text { Amino } \\
\text { acid }\end{array}$ \\
\hline 1 & 5'Upstream & $\begin{array}{l}5 \text { 'gaaccatgcagtagaacagg } \\
\text { 3'ctggaagtctgtagtcaagg }\end{array}$ & ${ }^{1} 5^{\prime} \mathrm{U}: \mathrm{A}-1082 \mathrm{G} \#$ & 0.033 & 0.064 & No & SSC1:289,774,983 & - & - \\
\hline 2 & & & ${ }^{1} 5^{\prime} \mathrm{U}: \mathrm{T}-1019 \mathrm{C \#}$ & 0.033 & 0.064 & No & SSC1:289,775,046 & - & - \\
\hline 3 & & & ${ }^{1} 5^{\prime} \mathrm{U}: \mathrm{C}-984 \mathrm{~T} \#$ & 0.033 & 0.064 & No & SSC1:289,775,081 & - & - \\
\hline 4 & & $\begin{array}{l}5 \text { 'cacaagaaggaagagatagc } \\
3^{\prime} \text { caccaagggaagctctagg }\end{array}$ & ${ }^{1} 5^{\prime} \mathrm{U}: \mathrm{C}-522 \mathrm{~T} \#$ & 0.133 & 0.244 & No & SSC1:289,775,543 & & \\
\hline 5 & & & ${ }^{1} 5^{\prime} \mathrm{U}: \mathrm{G}-400 \mathrm{~A}$ & 0.363 & 0.550 & rs80830544 & SSC1:289,775,665 & & \\
\hline 6 & & & ${ }^{1} 5^{\prime} \mathrm{U}: \mathrm{G}-75 \mathrm{C} \#$ & 0.025 & 0.056 & No & SSC1:289,775,979 & - & - \\
\hline 7 & Intron 2 & $\begin{array}{l}\text { 5'acagaagattggatggaagga } \\
3^{\prime} \text { gagataagaaagctgagacc }\end{array}$ & ${ }^{2} 2 \mathrm{I}: \mathrm{A} 232 \mathrm{C}$ & 0.004 & 0.029 & rs80881287 & SSC1:289,780,226 & - & - \\
\hline 8 & & & ${ }^{2} 2 \mathrm{I}: \mathrm{C} 298 \mathrm{~T} * *$ & 0.002 & 0.013 & rs80787918 & SSC1:289,780,292 & - & - \\
\hline 9 & Intron 2 & $\begin{array}{l}\text { 5'cctcacttgatatgtttgec } \\
\text { 3'gttcctccaggacagatttg }\end{array}$ & ${ }^{2} 2 \mathrm{I}: \mathrm{C} 2567 \mathrm{~T} \#$ & 0.001 & 0.025 & No & SSC1:289,782,761 & - & - \\
\hline 10 & Exon 3 & & ${ }^{3} \mathrm{C} 318 \mathrm{~A}$ & 0.003 & 0.037 & rs80923358 & SSC1:289,782,834 & - & - \\
\hline 11 & & & ${ }^{3} \mathrm{G} 417 \mathrm{~A}$ & 0.003 & 0.037 & rs80951861 & SSC1:289,782,933 & - & - \\
\hline 12 & & & ${ }^{3} \mathrm{~T} 611 \mathrm{~A}^{*}$ & 0.007 & 0.054 & rs80811682 & $\mathrm{SSC} 1: 289,783,127$ & 204 & $\mathrm{~L} / \mathrm{H}$ \\
\hline 13 & Exon 3 & $\begin{array}{l}5 \text { 'attcaaggtctggctggttc } \\
3^{\prime} \text { tgaagacatcaggaagcaag }\end{array}$ & ${ }^{3} \mathrm{G} 826 A^{*}$ & 0.285 & 0.514 & Shinkai et al. (2006) & SSC1:289,783,342 & 276 & $\mathrm{~V} / \mathrm{I}$ \\
\hline 14 & & & ${ }^{3} \mathrm{G} 960 \mathrm{~A}$ & 0.064 & 0.105 & rs80981701 & SSC1:289,783,476 & - & - \\
\hline 15 & & & ${ }^{3} \mathrm{G} 962 \mathrm{~A}^{*}$ & 0.034 & 0.046 & rs80955017 & SSC1:289,783,478 & 321 & $\mathrm{R} / \mathrm{H}$ \\
\hline 16 & & & ${ }^{3} \mathrm{C} 1027 \mathrm{~A}^{*}$ & 0.176 & 0.231 & rs80894552 & SSC1:289,783,543 & 343 & $\mathrm{Q} / \mathrm{K}$ \\
\hline & Exon 3 & $\begin{array}{l}\text { 5'acatccacgttgtcttccg } \\
3^{\prime} \text { 'cagttcattcctcacccag }\end{array}$ & - & & & & & - & - \\
\hline 17 & Exon 3 & $\begin{array}{l}5 \text { 'cttcctcetggtatctgtgg } \\
\text { 3'ggcagtcctgtgtatctcg }\end{array}$ & ${ }^{3} \mathrm{G} 2397 \mathrm{~A}$ & 0.025 & 0.056 & rs80834103 & SSC1:289,784,913 & - & - \\
\hline 18 & 3'Downstream & $\begin{array}{l}5 \text { 'actcccaacgtgtcccttg } \\
3^{\prime} \text { 'ccaagaagtgccactttcaac }\end{array}$ & ${ }^{4} 3^{\prime} \mathrm{D}: \mathrm{C} 208 \mathrm{~T}^{* *}$ & 0.002 & 0.011 & rs80907449 & $\mathrm{SSC} 1: 289,785,250$ & - & - \\
\hline
\end{tabular}

${ }^{1}$ to first codon of exon $1 ;{ }^{2}$ position in intron $2 ;{ }^{3}$ position in coding region; ${ }^{4}$ position in 3 UTR downstream of last codon; *non-synonymous SNPs; **haplotype components; \# novel SNPs

shedding in swine. Following haplotype construction, a stepwise regression using a backward-elimination process was performed to identify the effect of each associated SNP in relationship to the haplotype; in this test, all associated SNPs were included and excluded individually from the analysis, and the association of the haplotype was tested each time using PLINK.

\section{Results and discussion}

Huang et al. (2011) identified the TLR4-dependent set of genes (TLR4 regulon) as a major inducer of the transcriptional response in Salmonella persistently shedding pigs, and this TLR4 regulon was not significantly affected in the low shedding pigs. Thus, TLR4 is considered a potential candidate to analyze the association of genetic polymorphisms with the diverse phenotypic patterns of Salmonella shedding in swine.
In this study, two swine populations were investigated, NADC-40 and NADC-77 (Uthe et al. 2011), each population with 10 low and 10 persistent Salmonella shedding animals (Fig. 1). For the quantitative measurement of Salmonella shedding per pig, a cumulative measurement taken within days 2, 7, 14, and 20/21 pi was calculated (Huang et al. 2011). Sequencing analysis of those $40(n=40)$ animals identified 18 SNPs; 12 were previously described in the literature and/or annotated in GenBank and six are novel SNPs (Table 1). Five of the novel SNPs are located within the $5^{\prime}$ untranslated region (UTR) and one is within intron 2.

The swine TLR4 gene (9030 bp/SGSC Sscrofa10.2/ susScr3) is composed of three exons (93, 167, and 2266 bp). Taking together these results and the literature, 50 SNPs have been identified in TLR4, with 22 SNPs located in the coding regions (Thomas et al. 2006; Shinkai et al. 2006; Palermo et al. 2000; Pan et al. 2011; Bao et al. 2011; Shinkai et al. 2012). Of these 22 SNPs, nine are non-synonymous and 


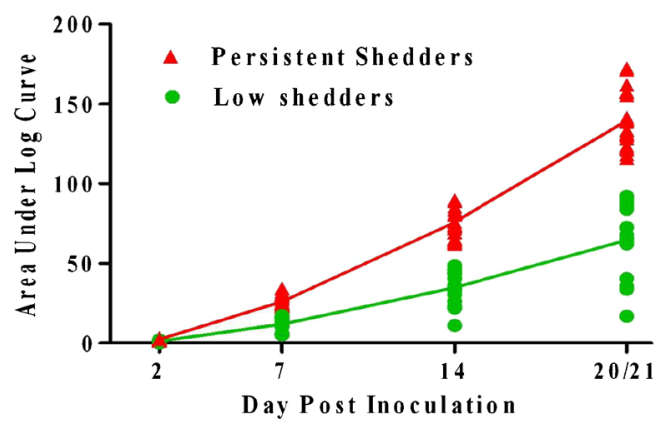

Fig. 1 Area under the log curve illustrating the log of cumulative colony forming units (CFU). Quantitative bacteriology of Salmonella shedding in swine fecal samples was performed at day 2, 7, 14, and 20/21 days post-challenge with Salmonella enterica serovar Typhimurium, and CFU were determined

located on exon 3. Our investigation identified four of those nine non-synonymous SNPs in exon 3 segregating in the NADC-40 and NADC-77 pig populations. Four segregating synonymous SNPs were also detected in exon 3.

Of the 18 SNPs identified in the two pig populations, 13 $(n=13)$ SNPs were associated $(P \leq 0.05)$ with Salmonella shedding as a qualitative phenotype using a Chi-squared test; of those 13 SNPs, seven were also associated with Salmonella shedding as a quantitative phenotype using a Wald statistical test (Table 1). Using a haplotype construction and the backward-elimination process, the most significant haplotype for both measurements of Salmonella shedding, qualitative $\left(P \leq 7.9 \times 10^{-4}\right)$ and quantitative $\left(P \leq 4.0 \times 10^{-3}\right)$ (Table 2) comprised a region of $4.9 \mathrm{~Kb}$ composed of SNPS, $r 580787918$ (SNP8) and $r s 80907449$ (SNP18) $\left(\mathrm{r}^{2}=0.902\right)$ located at SSC1:289,780,292 bp and SSC1:289,785,250 bp, respectively (Table 1).

Four SNPs, $r s 80811682$ (SNP12), SNP13, rs80955017 (SNP15), and rs80894552 (SNP16), located on exon 3 of TLR4 gene are non-synonymous mutations and they are positioned between markers rs80787918 (SNP8) and rs80907449 (SNP18). When the additive effect of those markers was tested within the haplotype constructed with markers rs80787918 (SNP8) and rs80907449 (SNP18), we did not observe any improvement in the association test. However, analyzing together the markers rs80787918 (SNP8), rs80811682 (SNP12), SNP13, rs80955017 (SNP15), rs80894552 (SNP16) and rs80907449 (SNP18), the haplotype composed of alleles (CTGGCC) was found in higher frequency $(65 \%)$ in persistent shedders than $31 \%$ in low shedders pigs $(P<0.003)$. Possibly, the addition of more markers in the haplotype is being penalized by the increased number of degrees of freedom and reduced number of samples per each class affecting the significance of our association results. To overcome this problem we tested multiple haplotypes with fewer markers per test. When markers SNP13 and rs80894552 (SNP16), which were not significant in the single marker association test, were removed from the haplotype, the significance improved to $P<0.001$. The haplotype composed of alleles CTGC was found in $65 \%$ of the high shedders and $30 \%$ of low shedders and the haplotype (TAAT) was found in $20 \%$ of the high shedders and $41 \%$ of the low shedders $(P<0.04)$. Finally, a specific haplotype (CTC) constructed with markers rs80787918 (SNP8), rs80811682 (SNP12) and $r s 80907449$ (SNP18), was observed in $65 \%$ of the persistent shedders and $30 \%$ on the low shedders pigs $(P<0.001)$. The opposite haplotype (TAT) was observed in $27.5 \%$ of the persistent shedders and in $59.4 \%$ of the low shedders pigs $(P<0.003)$.

A trend was observed between haplotypes constructed with markers: rs80787918 (SNP8), SNP13 and rs80907449 (SNP18) (CGC); rs80787918 (SNP8), rs80955017 (SNP15) and rs80907449 (SNP18) (CGC); rs80787918 (SNP8), rs80894552 (SNP16) and rs80907449 (SNP18) (CCC), where they were observed in $67.5 \%$ of the persistent shedders and $30 \%$ of low shedder pigs.

Haplotype CC of SNPS rs80787918 (SNP8) and $r s 80907449$ (SNP18) was identified in higher frequency in persistent shedding pigs $(67.5 \%: n=14)$ compared to low shedding pigs $(30 \% ; n=6)$; furthermore, the frequency of haplotype TT in low shedding pigs ( $65 \% ; n=13)$ was greater when compared to persistent shedding pigs $(32.5 \% ; n=6)$. No animals from the persistent shedding group were identified with the haplotype TC or CT, while it was observed in low frequency in the low shedding group (2.5\%). Together, these results suggest that the region located between markers $r s 80787918$ and $r s 80907449$, more specifically on exon 3 , is possibly harboring the causative mutation for Salmonella colonization and shedding variation in swine.
Table 2 Haplotypes frequency (SNPs $r s 80787918$ and rs80907449) and associations with qualitative and quantitative phenotypes of Salmonella shedding

\begin{tabular}{|c|c|c|c|c|}
\hline \multirow[b]{2}{*}{ Haplotype } & \multicolumn{2}{|l|}{ Haplotype frequency } & \multirow{2}{*}{$\begin{array}{l}\text { Qualitative } \\
P \text { value }\end{array}$} & \multirow{2}{*}{$\begin{array}{l}\text { Quantitative } \\
P \text { value }\end{array}$} \\
\hline & Persistent shedders & Low shedders & & \\
\hline $\mathrm{CC}$ & 0.675 & 0.3 & 0.00079 & 0.004201 \\
\hline $\mathrm{TC}$ & 0 & 0.025 & 0.3143 & 0.1054 \\
\hline $\mathrm{CT}$ & 0 & 0.025 & 0.3143 & 0.1445 \\
\hline TT & 0.325 & 0.65 & 0.00334 & 0.02912 \\
\hline
\end{tabular}




\section{Conclusion}

The results from this study support the concept that TLR4 is an important modulator associated with the porcine response to Salmonella infection in swine. Particularly interesting is that the haplotype with the highest significant association to the shedding phenotypes was found most often ( $65 \%)$ in the persistent shedder pigs than in low shedder pigs. Genetic variation in molecular functional regions, such as a ligand recognition site, can alter host resistance/susceptibility to specific pathogens (Uenishi et al. 2011). Furthermore, synonymous mutations in a gene can play a significant role in transcriptional regulation (Sauna and Kimchi-Sarfaty 2011; Sato et al. 2012). Thus, similar to Shinkai et al. (2011) who demonstrated polymorphisms in TLR5 and TLR2 alter the cellular response to $S$. Choleraesuis, our results highlight the importance of linking genetic variations that may influence the molecular function of a key transcriptional regulator (TLR4) with Salmonella shedding in swine.

Acknowledgments We thank Jennifer Jones for technical assistance. This project was supported by USDA, ARS CRIS funds, National Pork Board grant \#05-176, and by National Research Initiative competitive grant no.2009-35205-05192 from the USDA National Institute of Food and Agriculture Animal Genome Program.

Disclosure statements Mention of trade names or commercial products in this article is solely for the purpose of providing specific information and does not imply recommendations or endorsement by the U.S. Department of Agriculture.

USDA is an equal opportunity provider and employer.

Open Access This article is distributed under the terms of the Creative Commons Attribution License which permits any use, distribution, and reproduction in any medium, provided the original author(s) and the source are credited.

\section{References}

Bao WB, Ye L, Pan ZY et al (2011) Analysis of polymorphisms in the porcine TLR4 gene and its expression related to Escherichia coli F18 infection. Czech J Anim Sci 11:475-482

Ewing B, Hillier L, Wendl MC, Green P (1998) Base-calling of automated sequencer traces using phred. I. Accuracy assessment. Genome Res 8:175-185

Gordon D, Abajian C, Green P (1998) Consed: a graphical tool for sequence finishing. Genome Res 8:195-202

Huang T, Uthe JJ, Bearson SMD et al (2011) Distinct peripheral blood RNA responses to Salmonella in pigs differing in Salmonella shedding levels: intersection in IFNG, TLR and miRNA pathways. PloS ONE 6(12):e28786

[internet] http://www.phrap.org

Kataria RS, Tait RG Jr, Kumar D et al (2011) Association of tolllike receptor four single nucleotide polymorphisms with incidence of infectious bovine keratoconjunctivitis (IBK) in cattle. Immunogenetics 63(2):115-119

Leveque G, Forgetta V, Morroll S et al (2003) Allelic variation in TLR4 is linked to susceptibility to Salmonella enterica serovar Typhimurium infection in chickens. Infect Immun 71(3):1116-1124

Nickerson DA, Tobe VO, Taylor SL (1997) PolyPhred: automating the detection and genotyping of single nucleotide substitutions using fluorescence-based resequencing. Nucleic Acids Res 25(14):27452751

Noreen M, Shah MAA, Mall SM et al (2012) TLRT4 polymorphisms and diseases susceptibility. Inflamm Res 61:177-188

Palermo S, Capra E, Torremorell M et al (2000) Toll-like receptor 4 genetic diversity among pig populations. Anim Genet 40: 289-299

Pan ZY, Ye L, Zhu J et al (2011) Isolation of new alleles of the swine TLR4 gene and analysis of its genetic variation. Yi Chuan 33(2): 163-167, article in Chinese

Purcell S, Neale B, Todd-Brown K et al (2007) PLINK: a tool set for whole-genome association and population-based linkage analyses. Am J Hum Genet 81:559-575

Sato K, Yoshimura A, Kaneko T et al (2012) A single nucleotide polymorphism in 3'-untraslated region contribute to the regulation of Toll-like receptor 4 translation. J Biol Chem M111:338426

Sauna ZE, Kimchi-Sarfaty C (2011) Undesrtanding the contribuition of synonymous mutations to human diseases. Nat Rev Genet 12:684 691

Schröder NWJ, Schumann RR (2005) Single nucleotide polymorphisms of Toll-like receptors and susceptibility to infectious disease. Lancet Infect Dis 5:156-164

Shinkai H, Tanaka M, Morozumi T et al (2006) Biased distribuition of single nucleotide polymorphisms (SNPs) in porcine Toll-like receptor 1 (TLR1), TLR2, TLR4, TLR5 and TLR6 genes. Immunogenetics 58:324-330

Shinkai H, Suzuky R, Akiba M et al (2011) Porcine Toll-like receptors: recognition of Salmonella enterica serovar Choleraesuis and influence of polymorphisms. Mol Immunol 48:1114-1120

Shinkai H, Okumura N, Suzuki R et al (2012) Toll-like receptor 4 polymorphism impairing lipopolysaccharide signaling in Sus scrofa, and its restricted distribution among Japanese wild boar population. DNA Cell Biol 4:575-581

Thomas AV, Broes AD, Vandegaart HF et al (2006) Genomic structure, promoter analysis and expression of the porcine (Sus scrofa) TLR4 gene. Mol Immunol 43:653-659

Uenishi H, Shinkay H (2009) Porcine Toll-like receptors: the front line of pathogen monitoring and possible implications for disease resistance. Dev Comp Immunol 33:353-361

Uenishi H, Shinkai H, Morozumi T et al (2011) Genomic survey of polymorphisms in pattern recognition receptors and their possible relationship to infection in pigs. Vet Immunol Immunopathol 148: 69-73

Uthe JJ, Wang Y, Qu L et al (2009) Correlating blood immune parameters and CCT7 genetic variant with the shedding of Salmonella enterica serovar Typhimurium in swine. Vet Microbiol 135:384-388

Uthe JJ, Qu L, Couture O et al (2011) Use of bioinformatics SNP predictions in differentially expressed genes to find SNPs associated with Salmonella colonization in swine. J Anim Breed Genet 128: 354-365

Yang XQ, Murani E, Ponsuksili S et al (2012) Association of TLR4 polymorphism with cytokine expression level and pulmonary lesion in pigs. Mol Biol Rep 39:7003-7009

Zanella R, Settles ML, McKay SD et al (2011) Identification of loci associated with tolerance to Johne's disease in Holstein cattle. Anim Genet 42:28-38 